\title{
Underlying Structure of E-learning Readiness among Palestinian Secondary School Teachers
}

\author{
Fuad A.A.Trayek ${ }^{1}$, Tunku Badariah Tunku Ahmad ${ }^{1}$, Mohamad Sahari Nordin ${ }^{1}$, Mohammed AM Dwikat ${ }^{2}$, Enas Said Ali \\ Abulibdeh $^{3}$, Muath Asmar ${ }^{4}$ and Siti Salwa Md. Sawari ${ }^{5}$ \\ ${ }^{1}$ Kulliyyah of Education, International Islamic University Malaysia, 53100 KL, Malaysia \\ ${ }^{2}$ Faculty of Engineering \& Information Technology, An Najah National University Nablus, Palestine \\ ${ }^{3}$ Education Department, Al Ain University of Science and Technology, United Arab Emirates \\ ${ }^{4}$ Faculty of Economics \& Social Sciences, An Najah National University Nablus, Palestine \\ ${ }^{5}$ Faculty of Islamic Civilization, Universiti Teknologi Malaysia, Jalan Semarak, 54100 Kuala Lumpur Malaysia
}

\begin{abstract}
This paper reports on the results of an exploratory factor analysis procedure applied on the e-learning readiness data obtained from a survey of four hundred and seventy-five $(\mathrm{N}=475)$ teachers from secondary schools in Nablus, Palestine. The data were collected using a 23-item, self-developed Likert questionnaire measuring e-learning readiness based on Chapnick's conception of the construct. Principal axis factoring (PAF) with Promax rotation applied on the data extracted four distinct factors supporting four of Chapnick's e-learning readiness dimensions, namely technological, psychological, infrastructure, and equipment readiness. Together these four dimensions explained $56 \%$ of the variance. A reliability analysis produced high internal consistency estimates ranging between .81 (equipment readiness) and .91 (technological readiness) for the extracted factor structure. These findings provide sound empirical support for the construct validity of the items and for the existence of these four factors that measure e-learning readiness.
\end{abstract}

\section{Introduction}

E-learning is defined as content, materials and instruction delivered via all electronic and digital media, such as the Internet, intranet, satellite broadcasts, audio/videotapes, interactive TV and CD/DVD-ROM $[1,2]$. In recent years, elearning has emerged as an alternative platform to provide access to education to varied student populations, including deprived and disadvantaged groups. In some educational settings, e-learning may be the only viable solution to impart educational content to the masses, such as the case in Palestinian cities where teacher and student mobility is made difficult by Israeli occupation.

Caught in the midst of the long-standing IsraeliPalestinian conflict, Palestinian teachers face many difficulties in imparting education to their students. In many towns and cities in the country, Palestinian teachers and students experience restricted movement and mobility, created by checkpoints, roadblocks, and gated passages manned by Israeli soldiers and tanks [3]. Going to school daily is a challenging, sometimes dangerous, endeavour for teachers and students. This debilitating situation has paved the way for ICTs to be widely used among Palestinians to learn, communicate and exchange information. Given the political and physical scenario, e-learning constitutes an alternative instructional delivery method to be used in Palestine, which enables a larger population of her citizens to receive education.

\section{Literature Review}

E-learning refers to the use of the Internet, multiple forms of electronic media, and information and communication technologies (ICTs) to support and enhance learning in educational institutions. According to Soliman [4], elearning covers all ICT- and Internet-based teaching and learning methods used by educational institutions to enhance instructional quality and improve learning performance. An effective e-learning implementation should galvanize students greater towards independent modes of learning. But in educational settings, achieving a significant usage of elearning is influenced by many factors, and each institution has to study its ability and preparedness to adopt e-learning in the teaching and learning system. This ability or preparedness is called e-learning readiness, defined by Peters [5] as the degree to which an institution or organization is prepared on several key aspects to integrate ICT and e-learning into its system. Considering its role in determining the success of an e-learning initiative, the 
readiness factor must be thoroughly assessed before an institution decides to introduce e-learning.

In this study, e-learning readiness was defined as the ability and preparedness of Palestinian secondary school teachers to implement e-learning at their respective schools. Their readiness was measured in terms of their e-learning knowledge, computer skills, and positive beliefs about the benefits of e-learning. Tubaishat and Azzedine assert that elearning success can be achieved by understanding the needs and readiness of all stakeholders in a particular e-learning environment [6]. Towards this end, Chapnick outlined eight factors that can be considered in assessing e-learning readiness, namely psychological, sociological, environmental, human resource, financial, technological, equipment, and content readiness [7]. Darab and Montazer, on the other hand, suggested eleven key factors, i.e. policy, network, equipment, security, cultural, human resource, financial, technical infrastructure, content, standards, and management [8]. Five of their factors overlapped with those of Chapnick's.

Most key theorists maintain that it is very important to have relevant ICT training for teachers and instructors to enhance their preparedness and ability to take up e-learning [9]. Indeed, ICT-related factors are instrumental in shaping the success of e-learning, as highlighted by Bukaliya and Mubika [10], who found ICT knowledge and skills (in software and hardware), computer training, and infrastructure to be the main factors affecting teachers' readiness for the e-learning uptake in Zimbabwean schools. Quite recently three readiness dimensions, i.e. technological, psychological and equipment, were established as significant correlates of e-learning readiness, as they exercised quite a strong influence on teachers' ability to implement the initiative [11].

In contrast, other studies found no significant relationship between teachers' general readiness to embrace e-learning and their psychological predisposition towards it [12], suggesting that psychological readiness may not be quite as important as technical, content, or infrastructure readiness. In essence, however, the literature does suggest that several key factors come into place when considering elearning readiness. Although we are well-informed by the current research literature on readiness factors, there is still a need to understand the underlying structure that explains the nature of the construct, especially based on reports of teachers in war-torn places such as Palestine. Apart from obtaining an understanding of its underlying structure, this exercise also serves as a means to validate items that can be used to measure teachers' readiness to use e-learning.

\section{Objectives of the Study}

The objectives of this study were twofold. The first was to identify the underlying factor structure that could explain the e-learning readiness of Palestinian secondary school teachers. The second was to validate the e-learning readiness measurement scale based on the data.

\section{Methods}

\subsection{Respondents}

The study was a cross-sectional survey involving 475 teachers from the secondary schools in Nablus, Palestine. Female teachers made up $50.3 \%$ of the sample $(\mathrm{n}=239)$, while male teachers, $49.7 \%(n=236)$. The sample's mean age was 28.9 years.

\subsection{Instrument}

The readiness data were collected using a self-developed questionnaire that contained two parts. The first part requested demographic details of the respondents, while the second required the respondents to indicate their level of agreement to 23 items that measured e-learning preparedness in three aspects: psychological (7 items), technological (9 items), and equipment readiness ( 7 items). The items were primarily drawn from Chapnick's dimensions, as well as previous studies on e-learning, and measured the constructs on a 5-point Likert scale ranging from Strongly Agree (5) to Strongly Disagree (1). After content validation by five experts in the e-learning and educational research fields, the items were refined and pilot tested with 35 secondary teachers in Nablus.

\subsection{Data Collection and Analysis}

With the help of school principals, 554 copies of the questionnaire were distributed to all secondary school teachers in the city. Out of the 554 distributed, 475 were collected, constituting a response rate of $85.7 \%$. To extract the underlying structure of e-learning readiness, the data were subjected to a robust exploratory factor analysis procedure, i.e. Principal Axis Factoring (PAF). Stevens [13] explained that "the purpose of exploratory factor analysis is to identify the factor structure or model for a set of variables". In this analysis, PAF was deemed suitable to address the research objectives. Promax rotation, rather than Varimax, was used because it was anticipated that theoretically, the e-learning factors would be correlated. In addition, Matsunaga [14] suggests the use of Promax, rather than the more popular Varimax, as it is the most suitable and robust technique for data obtained in social science research.

\section{Results}

\subsection{Underlying Structure of e-Learning Readiness}

The PAF procedures applied on the data produced acceptable results in terms of sampling adequacy and interitem correlations. The Kaiser-Meyer-Olkin (KMO) measure of sampling adequacy, which ranges from 0 to 1 with the recommended cut-score of 0.7 , was 0.90 , indicating an adequate sampling adequacy for the application of PAF on the data. Bartlett's test of sphericity, which tests whether the correlation matrix is an identity matrix, was significant $(\chi 2=5972.1, \mathrm{df}=253, \mathrm{p}=.001)$, indicating that the overall correlations within the correlation matrix were adequate. In summary, these results show factorability of the data, hence justifying the use of PAF in the analysis. 
The scree plot drawn from the data (Figure 1) suggests that the items represented four underlying readiness factors. The eigenvalues of the factors and the total variance explained supported this four-factor structure.

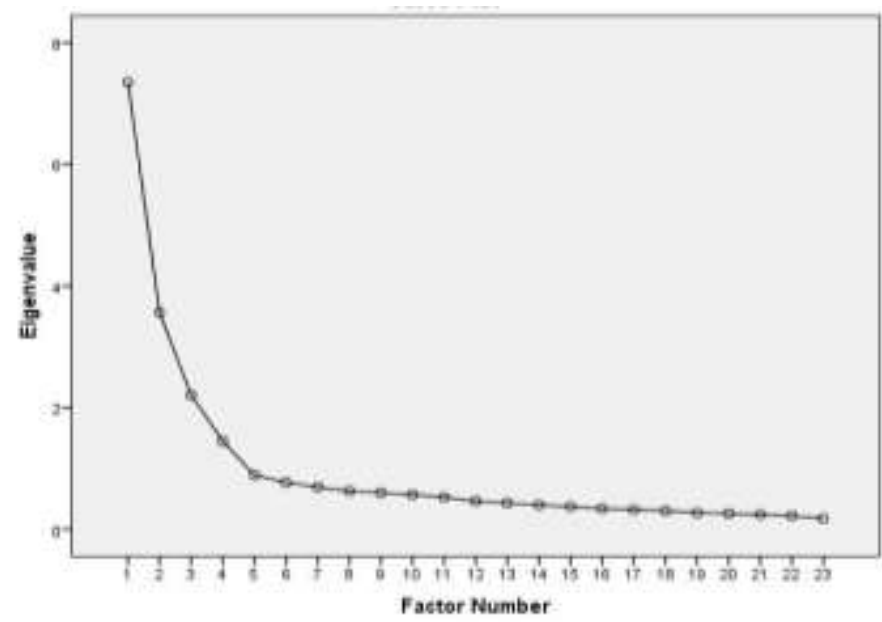

Figure 1.Scree Plot

An evaluation of the eigenvalue criteria with greater than 1.0 indicated the existence of four factors, which cumulatively explained $56 \%$ of the variance, with no crossloading. The correlations among items were significant with communalities ranging between .234 and .725 . Only four items (i.e. "I have the ICT facilities to implement e-learning in my classroom", "The school conducts ICT workshops to equip teachers with e-learning skills", "My school can provide the technical staff to support e-learning," and "The school's Internet connection is good") had a communality of less than 0.4 .

A total of 23 items were assigned to factors based on their highest level of loading. The first factor reflected teachers' technological readiness, and comprised eight items with loadings greater than 0.49 . The second factor reflected psychological readiness, comprising five items with loadings higher than 0.67 . The third factor consisted of seven items with loadings of more than 0.67; the factor suggested infrastructure readiness.

The fourth factor reflected equipment readiness, and contained three items with loadings of more than 0.58 . None of the items loaded highly on more than one factor. These findings provide empirical support for the validity of the readiness scale. The four factors are shown in Table 1 along with their representative items, factor loadings, eigenvalues, individual variance explained and communalities.

Table 1. The Four-Factor Structure with Factor Loadings, Eigenvalues, Variance Explained and Communalities

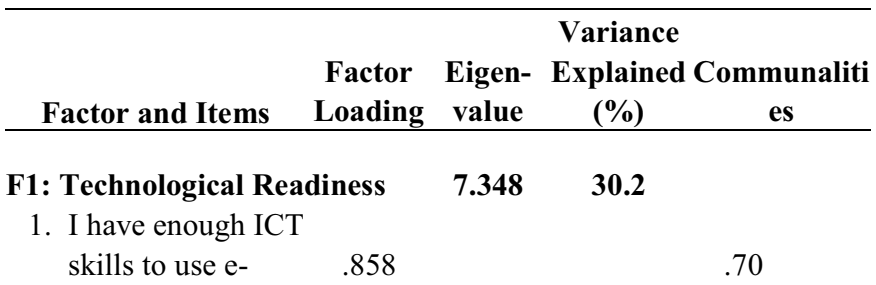

\section{learning}

2. Accessing the Internet is not a problem to me

3. I have the basic technical knowledge to fix technical elearning problems

4. I have enough ICT competencies to prepare e-learning materials

5. I know what elearning is

6. I clearly understand the components of elearning to use it for teaching

7. It is easy to acquire the skills to use e-learning

8. I am ready to integrate elearning in my teaching

F2: Psychological Readiness

1. Using e-learning for teaching is a good idea

2. I think e-learning can help students to be more active

3. I think e-learning is helpful to improve teaching and learning

4. I think e-learning is easy to use for teaching

5. It is easy to gain knowledge from the use of elearning to teach

F3: Infrastructure Readiness

1. I have the ICT facilities to conduct e-learning in my classroom 
Table 1. Continued

\begin{tabular}{|c|c|c|c|c|}
\hline Factor and Items & $\begin{array}{l}\text { Factor } \\
\text { Loading }\end{array}$ & $\begin{array}{l}\text { Eigen- } \\
\text { value }\end{array}$ & $\begin{array}{c}\text { Variance } \\
\text { Explained } \\
(\%)\end{array}$ & $\begin{array}{c}\text { Com } \\
\text { muna } \\
\text { lities } \\
\end{array}$ \\
\hline $\begin{array}{l}\text { 2. The school } \\
\text { conducts ICT } \\
\text { workshops to } \\
\text { equip teachers } \\
\text { with e-learning } \\
\text { skills } \\
\text { 3. My school can } \\
\text { provide the } \\
\text { technical staff to } \\
\text { support e-learning } \\
\text { 4. The school's } \\
\text { Internet } \\
\text { connection is good } \\
\text { 5. My school's ICT } \\
\text { infrastructure can } \\
\text { support e-learning } \\
\text { 6. My school has } \\
\text { enough computer } \\
\text { labs to support e- } \\
\text { learning } \\
\text { 7. The school's } \\
\text { computer labs } \\
\text { have up-to-date } \\
\text { facilities to } \\
\text { implement e- } \\
\text { learning }\end{array}$ & .534 & & & .60 \\
\hline $\begin{array}{l}\text { F4: Equipment Readin } \\
\text { 1. The school has } \\
\text { CD-ROM drives } \\
\text { that work well } \\
\text { 2. The school has } \\
\text { printers that work } \\
\text { well } \\
\text { 3. The school has } \\
\text { projectors that } \\
\text { work well }\end{array}$ & $\begin{array}{l}\text { less } \\
.587 \\
.837\end{array}$ & 1.446 & 4.3 & .55 \\
\hline
\end{tabular}

\subsection{Reliability of the e-Learning Readiness Data}

To generate the data's reliability estimates, Cronbach's alpha coefficients were calculated for the extracted structure. The results are shown in Table 2.

Table 2. Reliability of the Extracted Factor Structure

\begin{tabular}{rlcc}
\hline Factor & $\begin{array}{c}\text { No of } \\
\text { Items }\end{array}$ & $\begin{array}{c}\text { Cronbach's } \\
\text { Alpha }\end{array}$ \\
\hline 1. & Technological Readiness & 8 & .91 \\
2. & Psychological Readiness & 5 & .88 \\
3. & Infrastructure Readiness & 7 & .82 \\
4. & Equipment Readiness & 3 & .81 \\
\hline & Total & 23 & \\
\hline
\end{tabular}

All of the factors exhibited good internal consistency with coefficients greater than .80 , where an index of .70 or higher indicates a high internal consistency of the measurement scale [15]. Thus, it may be concluded that the e-learning readiness scale used in this study showed high internal consistencies as its extracted four-factor structured yielded estimates ranging between .81 and .91 . Therefore, the items may be relied on to produce reliable estimates of Palestinian teachers' e-learning readiness, and may be replicated in future studies measuring the same constructs.

\section{Conclusion}

In sum, the results produced a reliable four-factor structure of teachers' e-learning readiness, and supported three of Chapnick's dimensions, namely technological, psychological and equipment readiness, and two of Darab and Montazer's factors, namely infrastructure and equipment readiness. The results also provide empirical evidence in support of Akaslan and Law [9] and Bukaliya and Mubika [10], who established the importance of ICT skills and training in influencing readiness. This study found that technological capabilities explained slightly more than $30 \%$ of teachers' e-learning readiness. This finding is an important one as it highlights the crucial role of ICT skills and efficacy in determining teachers' ability to implement elearning. Second in importance is teachers' own beliefs that they can implement e-learning in their classroom, which is this study was shown to account for $13.5 \%$ of the variance explained.

In regard to validity of the readiness scale, the PAF results showed that all items had high factor loadings and could be categorized meaningfully into four logical factors, which cumulatively explained $56 \%$ of teachers' e-learning readiness. The total variance explained and the factor loadings suggest that the scale was successful in capturing the underlying dimensions of teachers' e-learning readiness. Thus, it can be reasonably argued that the scale provides a valid measure of the construct.

In addition, the Cronbach's alpha values for the factor structure were high (ranging from .81 to .91), suggesting that the scale has a high internal consistency. In conclusion, the reliability and validity results showed that the instrument developed for the study is a valid and reliable measurement tool that can be used to assess e-learning readiness in future studies. However, it would be more insightful for future researchers to consider other dimensions of Chapnick's and Darab and Montazer's models, such as human resource, content and financial readiness, which may be very instrumental in influencing teachers' uptake and implementation of e-learning in their classroom.

\section{References}

1. Clark, Ruth C., and Richard E. Mayer. "E-learning and the science of instruction: Proven guidelines for consumers and designers of multimedia learning." John Wiley \& Sons, 2011.

2. Govindasamy, T. "Successful implementation of elearning: pedagogical considerations." The Internet and Higher Education, 287-299, 2001. 
3. Trayek, F. A. A., TB Tunku Ahmad, and M. S. Nordin. "E-learning readiness and its correlates among secondary school teachers in Nablus, Palestine." Recent Trends in Social and Behaviour Sciences. Lumban Gaol et al. (Eds). London: Taylor \& Francis Group, 2014.

4. Soliman, Nagwa A. "Using E-Learning to Develop EFL Students' Language Skills and Activate Their Independent Learning." Creative Education, 752-757, 2014.

5. Peters, T. "E-Ready for What? E-readiness in developing countries: current status and prospects toward the millennium development goals." infoDev, bridges. Org, 2005.

6. Tubaishat, Abdallah, and Azzedine Lansari. "Are students ready to Adopt E-Learning? A Preliminary Ereadiness study of a University in the Gulf Region." International Journal of Information, 1 (5), 2011.

7. Chapnick, S (2000). "Are you ready for elearning?." Retrieved from http://www.gc21.de/ibt/en/site/ gc21 /ibt/permnent/publicforum/dok/are_you_ready_for_e learning.pdf on October 18, 2014.

8. Darab, B., and Gh A. Montazer. "An eclectic model for assessing e-learning readiness in the Iranian universities." Computers \& Education, 56 (3), 900-910, 2011.

9. Akaslan, Dursun, and E. L. Law. "Measuring Teachers' Readiness for E-learning in Higher Education Institutions associated with the Subject of Electricity." Proceedings of 2011 IEEE Global Engineering Education Conference: Learning Environments and Ecosystems in Engineering Education, EDUCON-2011, Amman, Jordan, 2011.

10. Bukaliya, Richard, and Augustine Kudakwashe Mubika. "Teacher competence in ICT: implications for computer education in Zimbabwean secondary schools." International Journal of Social Sciences and Education, 1(4), 414-425, 2011.

11. Trayek, F. A. A., TB Tunku Ahmad, and M. S. Nordin. "E-learning readiness and its correlates among secondary school teachers in Nablus, Palestine." Recent Trends in Social and Behaviour Sciences. Lumban Gaol et al. (Eds). London: Taylor \& Francis Group, 2014.

12. Mulwa, Angeline Sabina, and Dorothy Ndunge Kyalo. "The influence of principals', teachers'and students'attitude on readiness to adopt e-learning in secondary schools in kitui district, kenya." European Scientific Journal, 9 (5), 2013.

13. Stevens, J. "Applied multivariate statistics for the social sciences (3rd ed.)." Mahwah, NJ: Lawrence Erlbaum Associates, 1996.

14. Matsunaga, Masaki. "How to Factor-Analyze Your Data Right: Do's, Don'ts, and How-To's." International Journal of Psychological Research, 3 (1), 97-110, 2010.

15. Iacobucci, Dawn, and Adam Duhachek. "Advancing alpha: Measuring reliability with confidence." Journal of Consumer Psychology, 13 (4), 478-487, 2003. 